\title{
Endoscopic transcecal appendectomy
}

A 53-year-old woman was referred to our hospital after a 1-cm submucosal bulge near the appendiceal orifice ( $\triangleright$ Fig. 1 ) was incidentally found during a colonoscopy. The patient was asymptomatic. Her past medical history was significant only for acute appendicitis 20 years previously; she had suffered no complications, and had recovered fully with only conservative management. Endoscopic ultrasonography showed a hypoechoic lesion with an homogeneous echo, originating from the muscularis propria (॰ Fig. 2).

Since the lesion involved the appendix, endoscopic transcecal appendectomy was performed to obtain an accurate diagnosis. After submucosal injection of sodium hyaluronate mixed with adrenaline, an initial mucosal incision was made using a dual knife (Olympus), followed by full-thickness dissection. Next, circumferential dissection was continued along the outer surface of the appendix with an insulated-tip knife (IT2 knife; Olympus) and the dual knife, and this process eventually separated the appendix from the mesoappendix ( $\mathbf{F i g . 3}$ ). Under colonoscopic view, a 20-mL syringe with an 18-gauge needle was punctured into the abdominal cavity to release excess air. The completely resected appendix was pulled into the colon and was retrieved using a snare (> Fig.4). The defect was closed with endoloops and clips using the pursestring suture technique. The total procedure time was 90 minutes. Pathological examination confirmed chronic appendicitis. The patient was discharged 3 days later without complications. Follow-up colonoscopy was done at 1 month and showed the healing of the resection site ( $\mathbf{F i g . 5}$ ). No delayed complications were noted. Transvaginal and transgastric appendectomy have been reported in humans

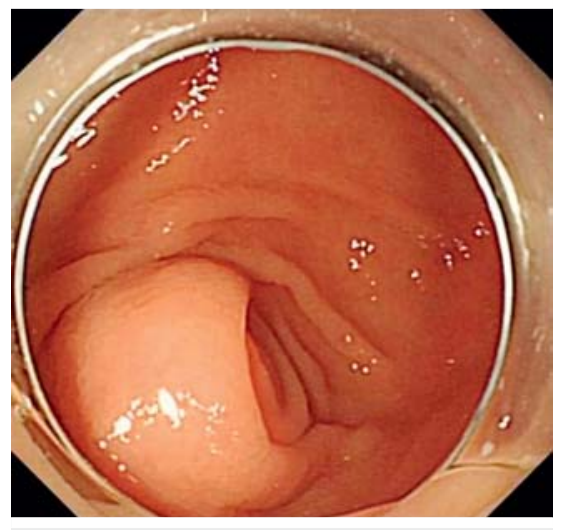

- Fig. 1 Colonoscopy revealed a $1-\mathrm{cm}$ submucosal bulge near the appendiceal orifice in an asymptomatic 53-year-old woman with a history of acute appendicitis 20 years previously.

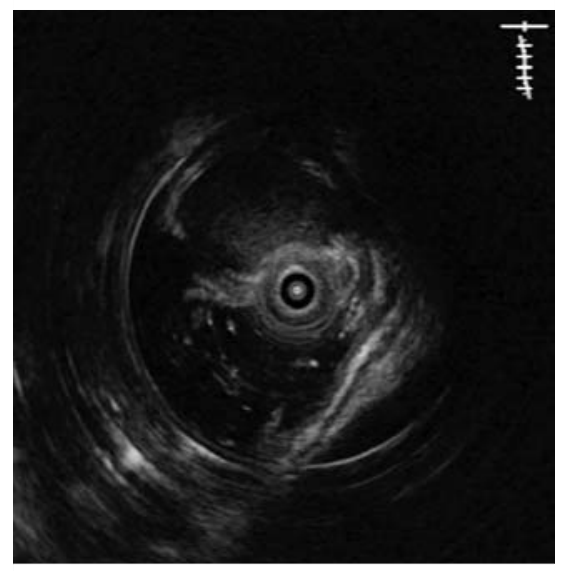

- Fig. 2 Endoscopic ultrasonography showed a hypoechoic lesion with an homogeneous echo, originating from the muscularis propria.

$[1,2]$, and these techniques generally require a hysteroscopy or laparoscopy. We present here a successful case of transcecal appendectomy via a colonoscopic approach. This method with no skin incision appears to be a good and promising

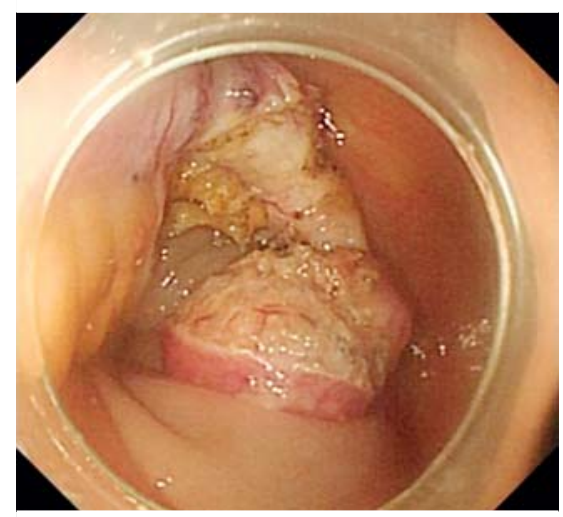

- Fig. 3 The appendix was successfully separated from the mesoappendix.

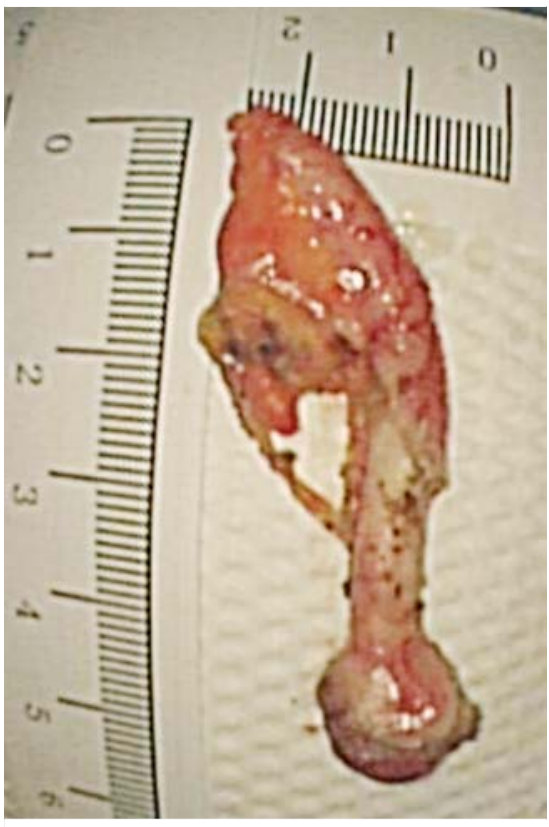

- Fig. 4 The resected appendix and lesion, measuring $5.5 \times 2.0 \mathrm{~cm}$.

option for treating appendiceal diseases. Further clinical studies with larger samples and long-term follow-up are needed to validate and assess its safety.

Endoscopy_UCTN_Code_TTT_1AQ_2AJ 


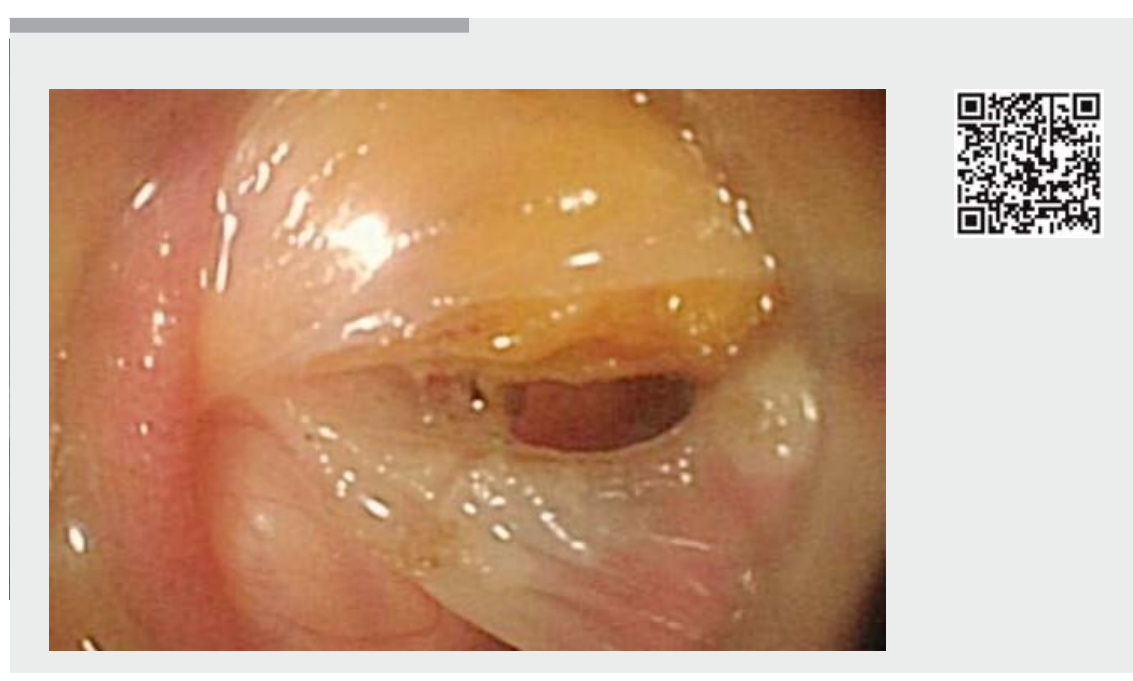

Video 1 Endoscopic transcecal appendectomy in a 53-year-old woman.

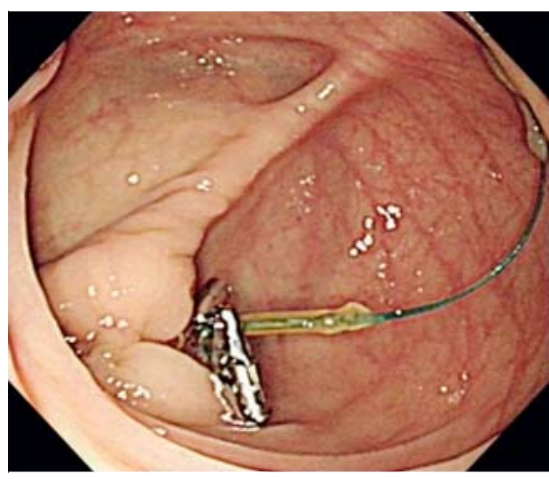

> Fig. 5 Postoperative colonoscopy 1 month later showed the healing of the resection site, and residual endoloops and clips.

\section{Acknowledgment}

The authors acknowledge funding support from Sichuan Province Science and Technology Department (China) (2017SZ0009).

All authors state they have no conflicts of interest relevant to this article.

The authors Lian-song $\mathrm{Ye}^{1}$, Bing $\mathrm{Hu}^{1}$

1 Department of Gastroenterology, West China Hospital, Sichuan University, Chengdu, China

2 San Bernardino Gastroenterology Associates, Rialto, California, USA

\section{Corresponding author}

\section{Bing Hu, MD}

Department of Gastroenterology, West

China Hospital, Sichuan University, No. 37

Guo Xue Xiang, Wu Hou District, Chengdu,
[1] Palanivelu C, Rajan PS, Rangarajan M et al. Transvaginal endoscopic appendectomy in humans: a unique approach to NOTES world's first report. Surg Endosc 2008; 22: $1343-1347$

[2] Park PO, Bergstrom M. Transgastric peritoneoscopy and appendectomy: thoughts on our first experience in humans. Endoscopy 2010; 42: 81-84

\section{Bibliography}

DOI https://doi.org/10.1055/a-0889-7289

Published online: 16.5 .2019

Endoscopy 2019; 51: 994-995

(c) Georg Thieme Verlag KG

Stuttgart · New York

ISSN 0013-726X

\section{ENDOSCOPY E-VIDEOS}

https://eref.thieme.de/e-videos

Xiang-lei Yuan ${ }^{1,}$, Onpan Cheung ${ }^{2,}{ }^{*}$, Jiang Du',

Sichuan 610041 , China

Fax: +86-028-85423387

hubingnj@163.com

* Co-first authors.
Endoscopy E-Videos is a free access online section, reporting on interesting cases and new techniques in gastroenterological endoscopy. All papers include a high quality video and all contributions are freely accessible online.

This section has its own submission website at

https://mc.manuscriptcentral.com/e-videos 